\title{
IONIZATION POTENTIALS OF ARGON, NITROGEN, CARBON MONOXIDE, HELIUM, HYDROGEN AND MERCURY AND IODINE VAPORS.
}

\author{
By Clifton G. Found
}

Synopsis.

Measurement of the Ionization potential of Gases was accomplished by means of a two electrode tube, by determining the point on the current-voltage curve at which the current increases at a rate faster than that given by Langmuir's equation

$$
i=A\left(V+V_{0}\right)^{3 / 2} \text {. }
$$

The effect of a voltage drop along the cathode was eliminated by a commutator arrangement which broke the filament heating circuit while the electron current was being measured.

The initial velocity of the electrons, $V_{0}$, was determined directly from the currentvoltage curve.

Ionization potentials were obtained by measurement as follows: Argon I 5.6, nitrogen I5.8, carbon monoxide I5.0, hydrogen I5.I, helium 20.5, mercury vapor I0.I, iodine vapor 8.5. The ionization potential of argon was found to be constant for pressures between I and 200 bars.

\section{INTRODUCTION.}

$\mathrm{IT}^{\mathrm{T}}$ has been shown by Langmuir ${ }^{1}$ that for a pure electron discharge, when the electrons start from the cathode with zero velocity, the maximum current which will pass to the anode is given by

$$
i=A V^{3 / 2} \text {, }
$$

where $V$ is the voltage on the anode and $A$ is a constant, depending only on the geometry of the tube.

The limitation of current is caused by space charge or the negative electrostatic field due to the electrons in the space between the electrodes. If in any way the effect of this negative space charge is neutralized, the current to the anode will increase with the voltage faster than the rate given by equation I. One way of neutralizing space charge is by the presence of positive ions. Hence, if an electron tube contains gas, as soon as positive ions are produced, the current increases more rapidly with increase of voltage, causing a point of discontinuity in the voltampere characteristic curve.

The voltage at which this kink occurs is a measure of the ionization potential of the contained gas.

\footnotetext{
1 Physical Review, Vol. it, No. 6, Dec., igi3.
} 
In the above reasoning, it was assumed that the electrons started with zero velocity, but in practice they are emitted with an initial velocity. If the average initial velocity is equal to a voltage $V o$, then equation (I) becomes

$$
\text { - } i=A\left(V+V_{0}\right)^{3 / 2} \text {. }
$$

Thus a voltage must be added to the observed voltage at which the kink occurs in order to obtain the true ionization potential. Tate and Foote, ${ }^{1}$ Foote and Mohler ${ }^{2}$ and others have determined the ionization potentials of a number of metallic vapors from the position of the kink in the voltampere characteristic curve. The value of $V_{0}$ they determined from measurements of resonance potentials.

The present method differs from that of Tate and Foote in that the ionization potential in this case is determined directly from equation (2) which does not hold rigorously for their arrangement. The facts that there was a difference of potential between the end of the cathode due to the heating current and also that a third electrode at a voltage negative to the anode was present, would prevent the current increasing, at low voltages, at a rate as high as that given by equation (2).

In order to eliminate the effect of a voltage drop along the filament, the present measurements were made with a rotating commutator. The diagram of connections is shown in Fig. I. The rotating commutator is

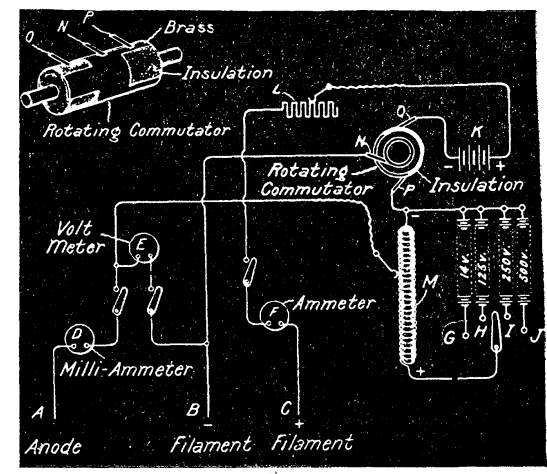

Fig. 1.

Diagram of electric connections for measuring the volt-ampere characteristics of vacuum tubes by use of rotating commutator.

so connected that no current can flow to the anode while the heating current is passing through the filament and the anode current is measured during the interval the heating circuit is broken. The speed of the com-

${ }^{1}$ Phil. Mag., 36, I918.

2 Phil. Mag., 37, Jan., I9I9. 
mutator is so great that there is no appreciable cooling of the filament during the intervals in which the heating current is off. The voltage of the anode and the anode current were measured on direct current instruments. Since these were on only a portion of the time, the readings obtained were average values and in order to obtain effective values, it is necessary to multiply the observed values by a constant-corresponding to the reciprocal of the fraction of the time during which current flowed. This constant was determined by taking the ratio of the voltage with commutator stopped, to the voltage reading with commutator running.

In all cases, the values given in the tables are effective values, obtained from the observed values by multiplying by the commutator constant. This varied from 2.1 8 to 2.22. The variation was due to resetting of the commutator brushes and in no case was a variation found during any series of measurements.

The electron tube which was used for these measurements consisted of two tungsten filaments, each wound in the form of a double helix, and molybdenum cylinder about $\mathrm{I} 2 \mathrm{~mm}$. diameter and $\mathrm{I} 2 \mathrm{~mm}$. long. The helices and cylinder were arranged coaxially. The inner helix, which was 5 turns of $0.125 \mathrm{~mm}$. wire wound on a $2.25 \mathrm{~mm}$. mandrel, was used as cathode. The outer helix, which had 3 turns of $0.125 \mathrm{~mm}$. wire wound on $3.65 \mathrm{~mm}$. mandrel, was connected to the molybdenum, cylinder and the combination was made the anode. This arrangement has the advantage that the electrons travel from the outer helix to the cylinder with a uniform velocity equivalent to the anode voltage so that when ionization takes place a larger number of positive ions is formed than if the outer helix were not present.

Since most of the positive ions travel to the cathode, a larger number is present in the region between the helices than would be present if the electrons did not travel over a large portion of their path with the maximum velocity corresponding to the anode voltage.

\section{Calculation of Ionization Potential.}

To determine the ionization potential of a gas, the volt-ampere characteristic of the tube was first taken with a good vacuum (about .oor bars), while it was still connected to a Langmuir condensation pump. The tube was then shut off from the pump by means of a mercury trap separated from the former by a liquid air trap and a known pressure of the gas let in. The characteristics were then taken again with the gas present.

The value of $V_{0}$ was calculated from equation (2). If $i_{1}$ and $i_{2}$ are the electron currents at two voltages $V_{1}$ and $V_{2}$ respectively, below the 
ionization potential, when gas was present, then

or

$$
\frac{i_{1}}{i_{2}}=\left\{\frac{V_{1}+V_{0}}{V_{2}+V_{0}}\right\}^{3 / 2}
$$

If $V_{2}=o$

$$
V_{0}=\frac{V_{1}-\left\{\frac{i_{1}}{i_{2}}\right\}^{2 / 3} V_{2}}{\left\{\frac{i_{1}}{i_{2}}\right\}^{2 / 3}-\mathrm{I}} .
$$

$$
V_{0}=\frac{V_{1}}{\left\{\frac{\left.i_{1}\right)}{\left.i_{2}\right)}\right\}^{2 / 3}-\mathrm{I}} .
$$

The value of $V_{0}$ was calculated from (3) and (4) for a number of observations and the average value taken. The values of $V_{0}$ for any characteristic curve did not differ by more than .2 volts.

It was found that the constant $A$ decreased when a relatively large pressure of gas was present. This can be accounted for by the increased distance the electrons have to travel in reaching the anode, due to collisions with the gas molecules. It is equivalent to an increase in the distance between electrodes. It was found, however, that the relation

$$
i=A\left(V+V_{0}\right)^{3 / 2}
$$

held up to the highest pressures at which measurements were taken. This was about I,000 bars for argon, helium, carbon monoxide and nitrogen, while for hydrogen and mercury and iodine vapors, the highest pressures were those given in the tables below. This is in agreement with the results of Richardson and Bazzoni, ${ }^{1}$ who found that the three halves power law held at low voltages in mercury vapor up to about $\mathrm{I} \mathrm{mm}$. pressure. In order to bring the characteristics when gas was present to correspond to those with a good vacuum, at voltages below ionization, it was found necessary to multiply the electron currents with gas by a constant $K$. The value of $K$ was determined by comparing values of $i$ at corresponding voltages below the ionization potential.

\section{ExPERIMENTAL REsULts.}

Table I. gives the tabulated results for argon, at a number of pressures. The values of $P, V_{0}$ and $K$ calculated as described above are given in the horizontal columns while vertically beneath them are given the values of $K i$ which are the observed values of the current multiplied by the factor $K$ in order that the results with different pressures may be comparable.

${ }^{1}$ Phil. Mag., 32, I916, p. 426. 
TABle I.

Argon.

\begin{tabular}{|c|c|c|c|c|c|c|}
\hline $\begin{array}{l}P \text { (Bars) } \ldots \ldots \\
V_{0}(\text { Volts }) \ldots \ldots \\
K \ldots \ldots \ldots \ldots\end{array}$ & $\begin{array}{l}.001 \\
.95 \\
1.00\end{array}$ & $\begin{array}{c}\mathbf{I} \\
\mathbf{I . 0} \\
\mathbf{I . 0 0}\end{array}$ & $\begin{array}{l}6.1 \\
\text { I.0 } \\
\text { I.00 }\end{array}$ & $\begin{array}{l}35 \\
1.0 \\
1.00\end{array}$ & $\begin{array}{l}80 \\
.95 \\
\times .06\end{array}$ & $\begin{array}{l}280 \\
.95 \\
\mathbf{x . 2 0}\end{array}$ \\
\hline$\left(V+V_{0}\right)^{3 / 2}$ & $K i$ & $K i$ & $K i$ & $K i$ & $K i$ & $K i$ \\
\hline 5.7 & .41 & .41 & .43 & .38 & .38 & .39 \\
\hline 12.2 & .95 & .89 & .92 & .90 & .90 & .90 \\
\hline 20.0 & 1.55 & 1.56 & 1.50 & 1.54 & 1.51 & 1.55 \\
\hline 24.8 & 1.85 & 1.85 & 1.84 & 1.85 & 1.85 & 1.83 \\
\hline 35.0 & 2.56 & 2.55 & 2.54 & 2.57 & 2.57 & 2.58 \\
\hline 46 & 3.36 & 3.31 & 3.32 & 3.35 & 3.30 & 3.25 \\
\hline 52 & 3.78 & 3.75 & 3.74 & 3.80 & 3.85 & 3.75 \\
\hline 58 & 4.22 & 4.20 & 4.19 & 4.22 & 4.22 & 4.23 \\
\hline 62 & 4.50 & 4.65 & 4.65 & 4.49 & 4.42 & 4.50 \\
\hline 64 & 4.75 & 4.85 & 4.81 & 4.85 & 4.60 & 4.80 \\
\hline 69 & 5.00 & 5.09 & 5.09 & 5.20 & 5.15 & 5.40 \\
\hline 71.5 & 5.28 & $5: 28$ & 5.28 & 5.53 & 6.10 & 6.85 \\
\hline 78 & 5.80 & 5.90 & 6.15 & 7.0 & 8.25 & 13.4 \\
\hline 86 & 6.20 & 6.55 & 6.55 & 8.9 & 13.1 & - \\
\hline 92 & 6.90 & 7.00 & 7.70 & 11.6 & 20.6 & - \\
\hline 100 & 7.20 & 7.65 & 8.80 & 15.5 & - & $\longrightarrow$ \\
\hline
\end{tabular}

Ionization potential $=(62)^{2 / 3}$ or 15.6 volts.

TABle II.

Argon.

\begin{tabular}{|c|c|c|c|c|c|}
\hline$P($ Bars $) \ldots \ldots$ & $l$ & 6.1 & 35 & 80 & 280 \\
\hline$\left(V+V_{0}\right)^{3 / 2}$ & $\Delta i$ & $\Delta i$ & $\Delta i$ & $\Delta i$ & $\Delta i$ \\
\hline 5.7 & .00 & .02 & -.03 & -.03 & -.02 \\
\hline 12.2 & -.06 & -.03 & -.05 & -.05 & -.05 \\
\hline 20.0 & .01 & -.05 & -.01 & -.04 & .00 \\
\hline 24.8 & .00 & -.01 & -.00 & .00 & -.02 \\
\hline 35.0 & -.01 & -.02 & +.01 & +.01 & +.02 \\
\hline 46.0 & -.05 & -.04 & -.01 & -.06 & -.11 \\
\hline 52.0 & .03 & -.04 & .02 & .07 & -.03 \\
\hline 58.0 & -.02 & -.03 & .00 & .00 & +.01 \\
\hline 62.0 & .15 & .15 & -.01 & -.08 & .00 \\
\hline 64 & .10 & .06 & .10 & -.15 & .05 \\
\hline 69 & .09 & .09 & .20 & .15 & .40 \\
\hline 71.5 & .00 & .00 & .25 & .82 & 1.57 \\
\hline 78 & .10 & .35 & 1.20 & 2.45 & 7.60 \\
\hline 86 & .35 & .35 & 2.7 & 6.9 & 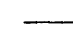 \\
\hline 92 & .1 & .80 & 4.7 & 13.7 & - \\
\hline 100 & .45 & 1.60 & 8.3 & - & - \\
\hline
\end{tabular}

Ionization potential $=(62)^{2 / 3}$ or 15.6 volts. 
The first vertical column gives the effective values of anode voltage raised to the three-halves power. Table II. gives the difference between the electron current in a good vacuum and that when gas is present.

Figure 2 gives the plot between the electron current and the effective

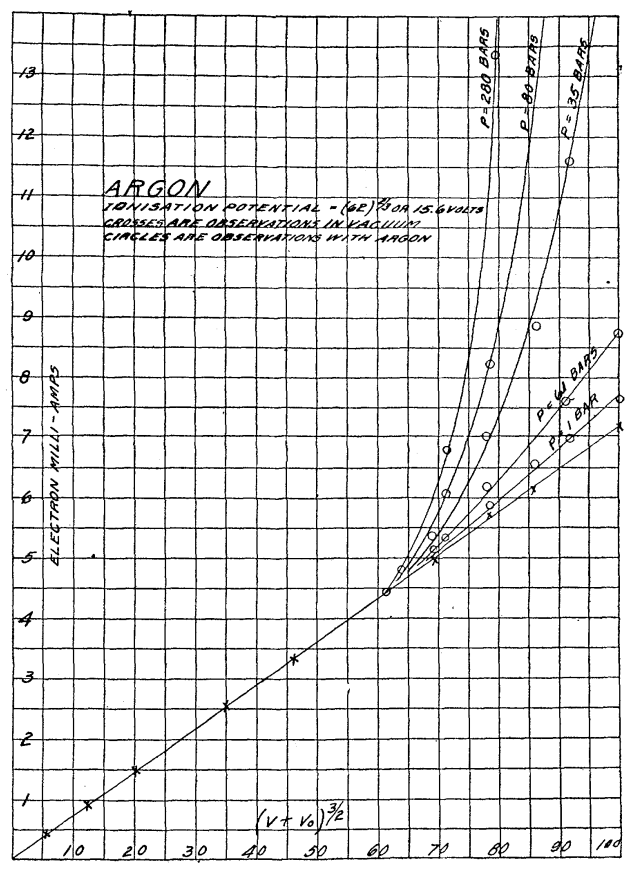

Fig. 2.

voltage raised to the three-halves power. It will be noted that the curve for a good vacuum is linear throughout the entire range while the curves when gas is present are linear only up to a certain point, above which the current increases faster than the linear relation. The curves for pressures from I to $28 \mathrm{o}$ bars apparently begin to depart from a straight line at the same point and the rate of departure increases with the pressure. At the lower pressures, it is difficult to tell the exact point at which the departure commences, but at the higher pressures the curve when gas is present meets that for a good vacuum at a sharp angle and there is no doubt where the effect of ionization sets in. For this reason, a high pressure of gas was used to determine the ionization potentials of the other gases.

Table III. contains the results for nitrogen. The first column gives the three-halves power of the effective voltage. The second and third 
give the corresponding values of the electron current with gas present and in a good vacuum, while the last column gives the difference between columns two and three. Figure 3 shows plot of results with nitrogen.

TABLe III.

Nitrogen.

\begin{tabular}{|c|c|c|c|}
\hline $\begin{array}{l}P(\text { Bars }) \ldots \ldots \ldots \ldots \ldots \\
V_{0}(\text { Volts }) \ldots \ldots \ldots \ldots \ldots \ldots \\
K \ldots \ldots \ldots \ldots \ldots \ldots \ldots\end{array}$ & $\begin{array}{r}300 \\
1.6 \\
1.14 \\
\end{array}$ & $\begin{array}{l}.001 \\
\text { I.I } \\
\text { I.00 }\end{array}$ & \\
\hline$\left(V+V_{0}\right)^{3 / 2}$ & $K i$ & $i$ & $\Delta i$ \\
\hline 4.45 & .35 & -.31 & .04 \\
\hline 10.9 & .76 & .74 & .02 \\
\hline 18.8 & 1.36 & 1.29 & .07 \\
\hline 28.0 & 1.96 & 1.92 & .04 \\
\hline 38.6 & 2.65 & 2.68 & -.03 \\
\hline 50.5 & 3.40 & 3.43 & -.03 \\
\hline 53 & 3.60 & 3.64 & -.04 \\
\hline 56 & 4.00 & 3.84 & .16 \\
\hline 59.5 & 4.20 & 4.08 & .12 \\
\hline 63 & 4.45 & 4.32 & .13 \\
\hline 66 & 5.10 & 4.52 & .58 \\
\hline 69 & 6.50 & 4.74 & 1.76 \\
\hline 73 & 8.40 & 5.00 & 3.40 \\
\hline 76 & 11.6 & 5.20 . & 6.40 \\
\hline
\end{tabular}

Ionization potential $=(63)^{2 / 3}$ or 15.8 volts.

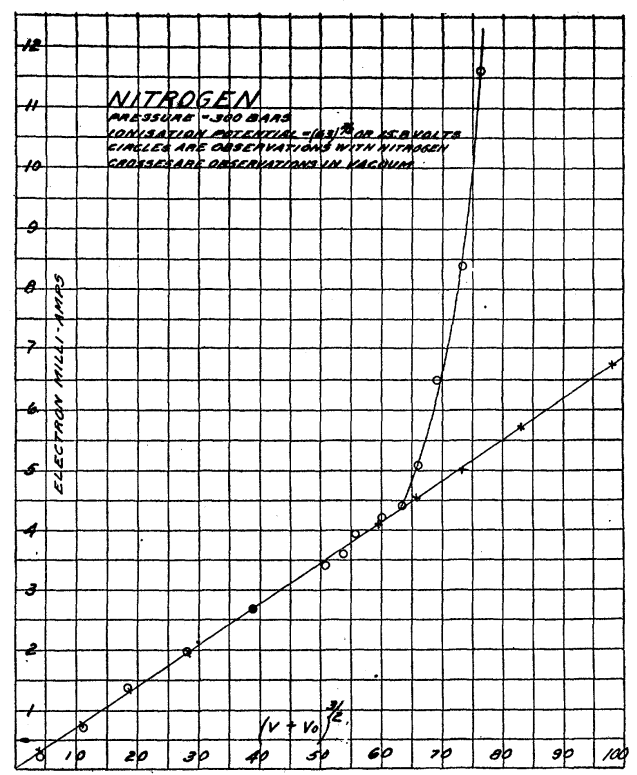

Fig. 3. 
Tables IV., V., VI., VII., VIII. give the results for carbon monoxide, hydrogen, helium, mercury vapor and iodine vapor respectively, while Figs. 4, 5, 6, 7 and 8 give the corresponding curves.

TABLE IV.

Carbon Monoxide.

\begin{tabular}{|c|c|c|c|}
\hline $\begin{array}{l}P \text { (Bars) } \\
V_{0} \\
K_{1}\end{array}$ & $\begin{array}{r}200 \\
2.2 \\
1.03 \\
\end{array}$ & $\begin{array}{l}.001 \\
\text { I.I } \\
\text { I.0O }\end{array}$ & \\
\hline$\left(V+V_{0}\right)^{3 / 2}$ & $K i$ & $i$ & $\Delta i$ \\
\hline 6.0 & .51 & .57 & -.06 \\
\hline 12.9 & 1.14 & 1.19 & -.05 \\
\hline 21.5 & 1.90 & 1.96 & -.06 \\
\hline 31 & 2.80 & 2.80 & .00 \\
\hline 42 & 3.65 & 3.68 & -.03 \\
\hline 51 & 4.55 & 4.55 & .00 \\
\hline 54 & 4.85 & 4.85 & .00 \\
\hline 58 & 5.10 & 5.10 & .00 \\
\hline 61 & 6.00 & 5.40 & .60 \\
\hline 64 & 8.20 & 5.55 & 2.65 \\
\hline 67 & 12.00 & 5.82 & 6.18 \\
\hline 74 & 20.6 & 6.60 & 14.0 \\
\hline 81 & 32.0 & 7.38 & 24.6 \\
\hline
\end{tabular}

Ionization potential $=(58)^{2 / 3}$ or 15 . volts.

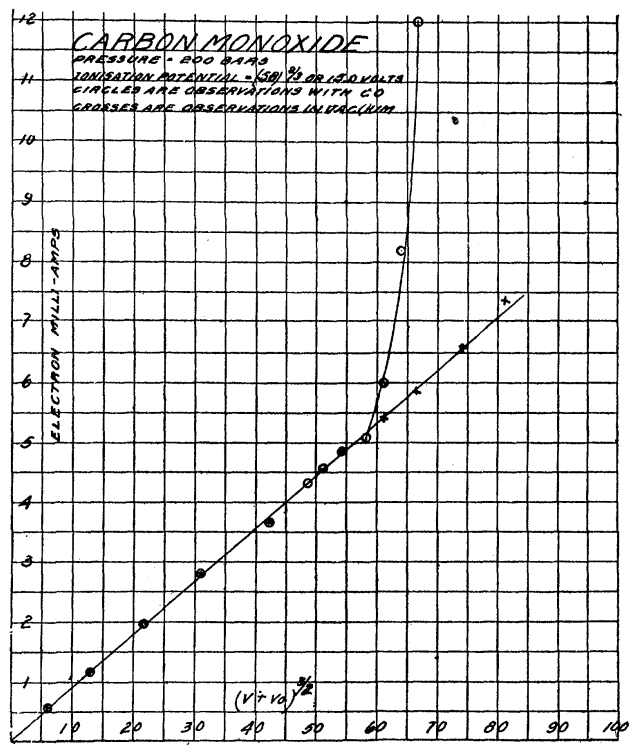

Fig. 4. 
TABLE V.

Hydrogen.

\begin{tabular}{|c|c|c|c|}
\hline $\begin{array}{l}P(\text { Bars }) \ldots \ldots \ldots \ldots \\
V_{0}(\text { Volts }) \ldots \ldots \cdots \cdots \\
K \ldots \ldots \ldots \ldots \ldots\end{array}$ & $\begin{array}{l}135 \\
2.5 \\
1.2\end{array}$ & $\begin{array}{l}.001 \\
1.1 \\
1.00\end{array}$ & \\
\hline$\left(V+V_{0}\right)^{3 / 2}$ & $K i$ & $i$ & $\Delta i$ \\
\hline 6.8 & .38 & .48 & .10 \\
\hline 13.7 & 1.00 & .95 & -.05 \\
\hline 22.0 & 1.58 & 1.52 & .06 \\
\hline 31.5 & 2.23 & 2.18 & .05 \\
\hline 40 & 2.75 & 2.75 & .00 \\
\hline 48 & 3.35 & 3.32 & .03 \\
\hline 54 & 3.78 & 3.74 & .04 \\
\hline 57 & 4.01 & 3.96 & .05 \\
\hline 60 & 4.22 & 4.17 & .05 \\
\hline 63 & 4.45 & 4.38 & .07 \\
\hline 65 & 4.70 & 4.52 & .18 \\
\hline 68 & 5.10 & 4.72 & .38 \\
\hline 73 & 5.63 & 5.06 & .57 \\
\hline 86 & 8.00 & 5.92 & 2.08 \\
\hline
\end{tabular}

Ionization potential $=(59)^{2 / 3}$ or 15.1 volts.

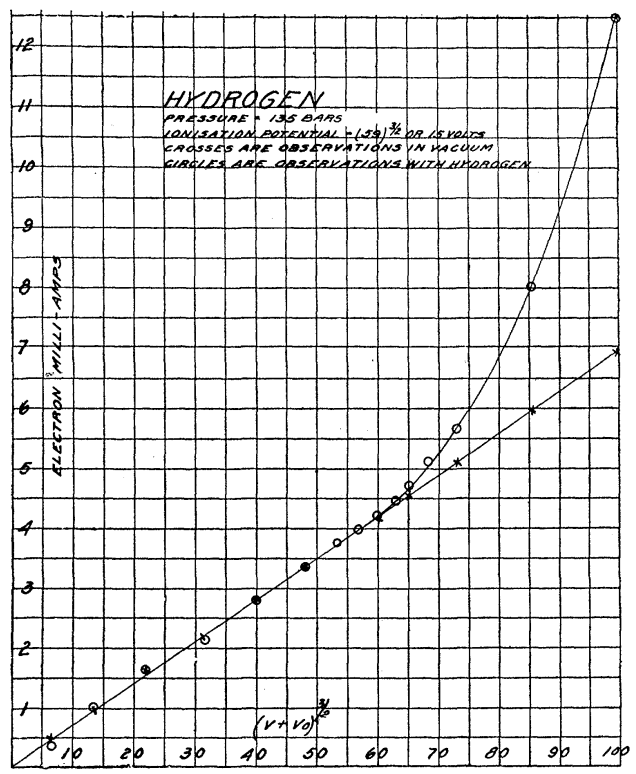

Fig. 5. 
TABle VI.

Helium.

\begin{tabular}{|c|c|c|c|}
\hline $\begin{array}{l}P \text { (Bars) } \ldots \ldots \ldots \ldots \\
V_{0}(\text { Volts }) \ldots \ldots \cdots \cdots \\
K \ldots \ldots \ldots \ldots \ldots \\
\end{array}$ & $\begin{array}{r}650 \\
2.2 \\
1.60 \\
\end{array}$ & $\begin{array}{l}\text { Vacuum } \\
2.2 \\
1.00 \\
\end{array}$ & . \\
\hline$\left(V+V_{0}\right)^{3 / 2} \ldots \ldots \ldots$ & $K i$ & $i$ & $\Delta i$ \\
\hline 6 & .123 & .176 & -.53 \\
\hline 13 & .220 & .275 & -.55 \\
\hline 21.5 & .358 & .385 & -.27 \\
\hline 31.1 & .520 & .530 & -.10 \\
\hline 42 & .700 & .700 & .00 \\
\hline 54 & .91 & .900 & .10 \\
\hline 67 & 1.12 & 1.12 & .00 \\
\hline 74 & 1.28 & 1.23 & .05 \\
\hline 81 & 1.47 & 1.36 & .11 \\
\hline 88 & 1.68 & 1.50 & .18 \\
\hline 96 & 1.95 & 1.60 & .35 \\
\hline 103 & 2.47 & 1.74 & .73 \\
\hline 112 & 3.10 & 1.85 & 1.25 \\
\hline 120 & 3.68 & 1.96 & 1.72 \\
\hline
\end{tabular}

Ionization potential $=(94)^{2 / 3}$ or 20.5

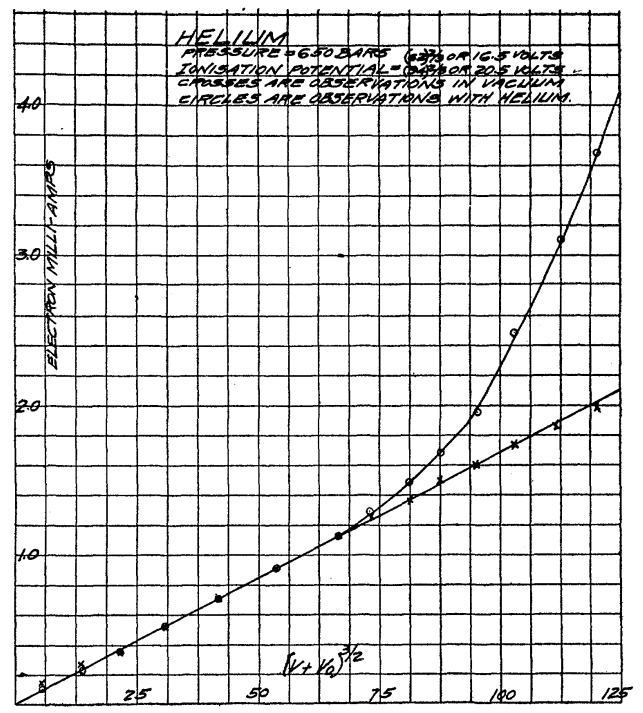

Fig. 6. 
TABLE VII.

Mercury Vapor.

\begin{tabular}{|c|c|c|c|}
\hline 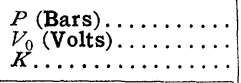 & $\begin{array}{c}2.0 \\
2.75 \\
2.0\end{array}$ & $\begin{array}{l}.001 \\
2.2 \\
1.0\end{array}$ & \\
\hline$\left(V+V_{0}\right)^{3 / 2}$ & $K i$ & $i$ & $\Delta i$ \\
\hline 4.6 & .84 & .84 & .00 \\
\hline 11.2 & 2.15 & 2.15 & .00 \\
\hline 15 & 2.75 & 2.85 & -.10 \\
\hline 19.4 & 3.63 & 3.74 & -.11 \\
\hline 24.0 & 4.45 & 4.55 & -.10 \\
\hline 26.5 & 5.20 & 5.20 & .00 \\
\hline 29 & 5.80 & 5.60 & .20 \\
\hline 32 & 6.20 & 6.10 & .10 \\
\hline 33 & 6.65 & 6.40 & .25 \\
\hline 34 & 7.20 & 6.50 & .70 \\
\hline 35 & 8.20 & 6.70 & 1.50 \\
\hline 36 & 9.50 & 6.85 & 2.65 \\
\hline 37 & 11.0 & 7.09 & 3.91 \\
\hline
\end{tabular}

Ionization potential $=(32)^{2 / 3}$ or 10.1 volts.

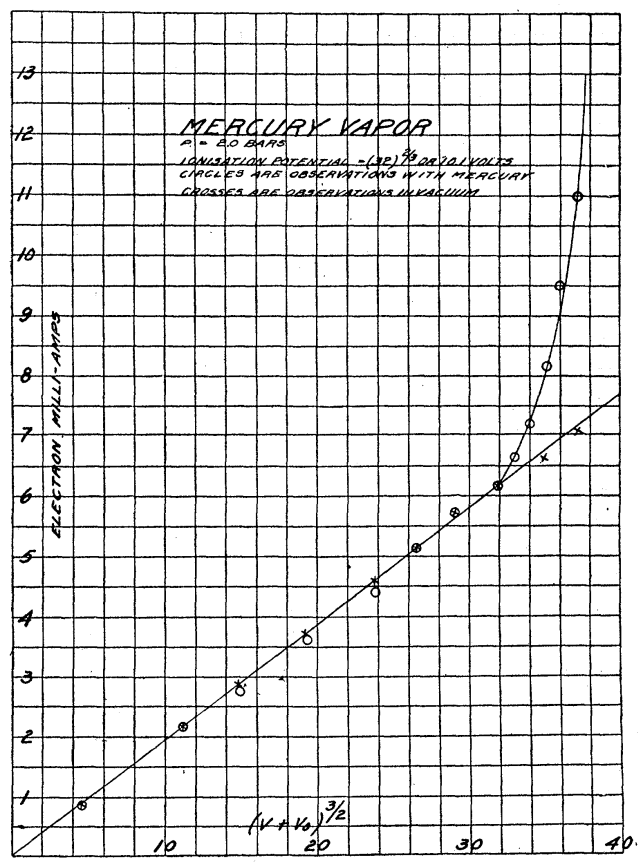

Fig. 7. 
TABLE VIII.

Iodine Vapor.

\begin{tabular}{|c|c|c|c|}
\hline $\begin{array}{l}P_{P}(\text { Bars }) \\
V_{0}(\text { Volts) } \ldots \ldots \ldots \ldots \ldots \\
K \ldots \ldots \ldots \ldots \ldots\end{array}$ & $\begin{array}{l}40 \\
.35 \\
2.5\end{array}$ & $\begin{array}{l}.001 \\
\text { r.6 } \\
\text { I.0 }\end{array}$ & \\
\hline$\left(V+V_{0}\right)^{3 / 2} \ldots \ldots \ldots$ & $K i$ & $i$ & $\Delta i$ \\
\hline 4.3 & .35 & .32 & .03 \\
\hline 10.9 & .78 & .77 & .01 \\
\hline 19.4 & 1.44 & 1.45 & -.01 \\
\hline 24.2 & 1.80 & 1.80 & .00 \\
\hline 25.0 & 1.90 & 1.87 & .03 \\
\hline 26.1 & 2.00 & 1.95 & .05 \\
\hline 27.2 & 2.10 & 2.03 & .07 \\
\hline 28.2 & 2.30 & 2.10 & .20 \\
\hline 29.5 & 2.40 & 2.25 & .15 \\
\hline 30.5 & 2.54 & 2.32 & .22 \\
\hline 31.5 & 2.77 & 2.40 & .37 \\
\hline 32.6 & 3.25 & 2.48 & .77 \\
\hline 33.5 & .3 .75 & 2.57 & 1.18 \\
\hline 37.0 & 5.25 & 2.80 & 2.45 \\
\hline
\end{tabular}

Ionization potential $=(25)^{2 / 3}$ or 8.5 volts.

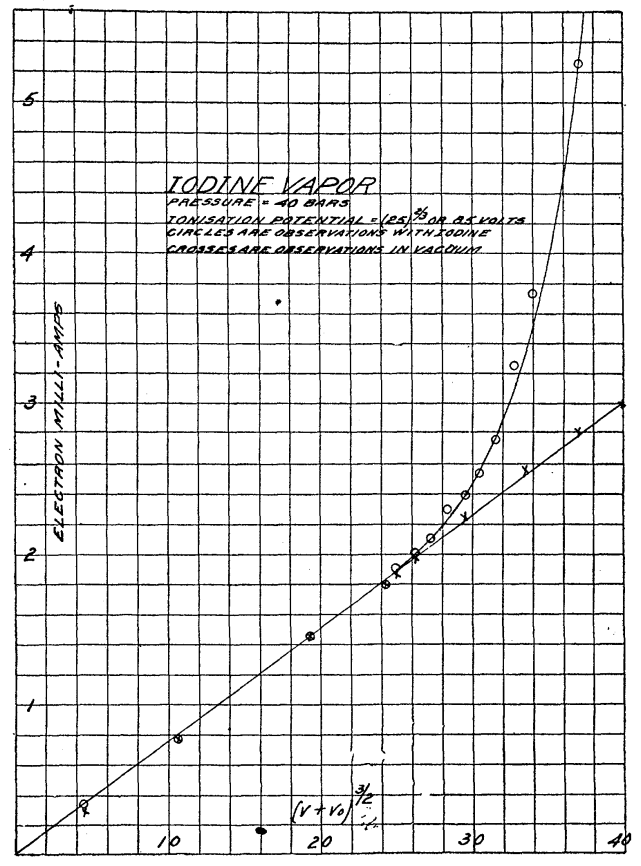

Fig. 8. 
The curve for helium shows two kinks, the first one at $\mathrm{I} 6.5$ volts and the second at about 20 volts. One explanation that might be given for these results is that helium has two types of ionization, a weak one occurring at 16.5 volts and a more intense one at 20 volts. Since no other experimenter has found ionization in helium as low as 16.5 volts, it seems more probable that this value is due to a slight impurity in the helium, although the latter was purified by passing through charcoal at the temperature of liquid air. The helium used was known to contain a slight admixture of neon, which would not be removed, as it passed through the charcoal at the temperature of liquid air. Since it would require only about 6 bars or I per cent. of neon to account for the magnitude of the kink at I6.5 volts, it seems very probable that this kink is due to ionization of the neon content, while the ionization potential of helium is given by the second kink at 20.5 volts.

\section{SUMMARY.}

I. It has been shown that the relation

$$
i=A(V+V o)^{/ 32}
$$

holds for the electron tube used in these experiments when no gas is present.

2. When gas is present, the above relation holds up to a certain voltage corresponding to the ionization potential of the gas, beyond which the current increases at a faster rate than given by the equation.

3. From the location of the point of departure from the above relation, the ionization potentials given in Table IX. were determined.

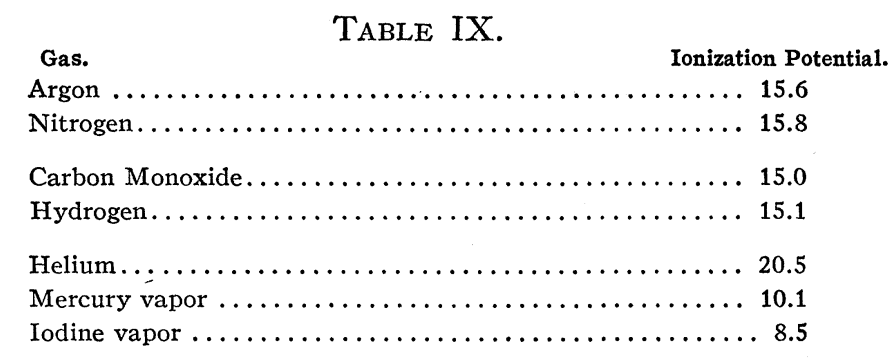

In conclusion, the writer wishes to express his appreciation of the kindly interest taken in these experiments by Dr. Langmuir, whose suggestions proved most valuable.

RESEARCH LABORATORY,

General Electric Co.,

SCHENECTADY, N. Y. 